\title{
Possible Involvement of the Drug Transporters P Glycoprotein and Multidrug Resistance-Associated Protein Mrp2 in Disposition of Azithromycin
}

\author{
Masami Sugie, ${ }^{1}$ Emiko Asakura,${ }^{1}$ Ying Lan Zhao, ${ }^{1,2}$ Shoko Torita,${ }^{1}$ Masayuki Nadai, ${ }^{3}$ Kenji Baba, \\ Kiyoyuki Kitaichi, ${ }^{1}$ Kenji Takagi, ${ }^{1}$ Kenzo Takagi, ${ }^{1}$ and Takaaki Hasegawa ${ }^{1 *}$ \\ Department of Medical Technology, Nagoya University School of Health Sciences, Higashi-ku, Nagoya 461-8673, ${ }^{1}$ Faculty of \\ Pharmacy, Meijo University, 150 Yagotoyama, Tenpaku-ku, Nagoya 468-8503, ${ }^{3}$ and Third Department of Internal Medicine, \\ Aichi Medical School, School of Medicine, Aichi-gun, Aichi 480-1195, ${ }^{4}$ Japan, and National Safety Assessment Center \\ of Traditional Chinese Medicine, West China Hospital, Sichuan University, Chengdu 610041, China ${ }^{2}$
}

Received 15 May 2003/Returned for modification 8 September 2003/Accepted 25 November 2003

\begin{abstract}
P glycoprotein and multidrug resistance-associated protein 2 (Mrp2), ATP-dependent membrane transporters, exist in a variety of normal tissues and play important roles in the disposition of various drugs. The present study seeks to clarify the contribution of $P$ glycoprotein and/or Mrp2 to the disposition of azithromycin in rats. The disappearance of azithromycin from plasma after intravenous administration was significantly delayed in rats treated with intravenous injection of cyclosporine, a P-glycoprotein inhibitor, but was normal in rats pretreated with intraperitoneal injection erythromycin, a CYP3A4 inhibitor. When rats received an infusion of azithromycin, cyclosporine and probenecid, a validated Mrp2 inhibitor, significantly decreased the steady-state biliary clearance of azithromycin to 5 and $40 \%$ of the corresponding control values, respectively. However, both inhibitors did not alter the renal clearance of azithromycin, suggesting the lack of renal tubular secretion of azithromycin. Tissue distribution experiments showed that azithromycin is distributed largely into the liver, kidney, and lung, whereas both inhibitors did not alter the tissue-to-plasma concentration ratio of azithromycin. Significant reduction in the biliary excretion of azithromycin was observed in Eisai hyperbilirubinemic rats, which have a hereditary deficiency in Mrp2. An in situ closed-loop experiment showed that azithromycin was excreted from the blood into the gut lumen, and the intestinal clearance of azithromycin was significantly decreased by the presence of cyclosporine in the loop. These results suggest that azithromycin is a substrate for both P glycoprotein and Mrp2 and that the biliary and intestinal excretion of azithromycin is mediated via these two drug transporters.
\end{abstract}

P glycoprotein, an ATP-binding cassette transport protein, exists constitutively in a variety of normal tissues such as the liver, kidney, small intestine, and capillary endothelium in the brain $(22,23,30)$ and plays an important role in the disposition of hydrophobic and cationic anticancer drugs. Like P glycoprotein, multidrug resistance-associated protein 2 (Mrp2) is also expressed in almost the same tissues as $\mathrm{P}$ glycoprotein $(4,16)$. This drug-transporting protein also acts as an active efflux pump for a wide range of organic anions, such as glutathione, glucuronate, and sulfate conjugates, by an ATP-dependent mechanism (20). Thus, both drug transporters appear to play key roles in the absorption, distribution, and elimination of various drugs.

It is known that the macrolide antibiotics erythromycin and clarithromycin inhibit not only CYP3A4 but also P glycoprotein $(11,21,34,37)$. We previously reported that many macrolide antibiotics, including erythromycin and clarithromycin, can overcome P-glycoprotein-dependent anticancer drug resistance and cause profound alterations in the pharmacokinetics of doxorubicin and grepafloxacin, which are substrates for $\mathrm{P}$ glycoprotein $(15,35,38)$. Azithromycin possesses unique phar-

\footnotetext{
* Corresponding author. Mailing address: Department of Medical Technology, Nagoya University School of Health Sciences, 1-1-20 Daikominami, Higashi-ku, Nagoya 461-8673, Japan Phone: 81-52-7193008. Fax: 81-52-719-3009. E-mail: hasegawa@met.nagoya-u.ac.jp.
}

macokinetic characteristics with a longer half-life, greater tissue distribution, and higher intracellular concentration than other known macrolide antibiotics $(7,9,19)$. This antibiotic is mainly eliminated in unchanged form in the feces via biliary excretion and intestinal secretion, whereas urinary excretion is the minor elimination route in humans (26). Some interesting clinical studies have reported that the pharmacokinetics of azithromycin are not influenced by the CYP3A4 inhibitor zafirlukast (8) and that azithromycin has no effect on the pharmacokinetics of triazolam, a substrate for CYP3A4 (14). It has also been reported that nelfinavir, a P-glycoprotein substrate, increases the intestinal absorption of azithromycin by inhibiting $\mathrm{P}$ glycoprotein in humans (1) and that P-glycoprotein inhibitors increase cellular accumulation of azithromycin in $\mathrm{J774}$ murine macrophages (25). Most recently, we have reported that azithromycin increases the intracellular accumulation of the P-glycoprotein substrate doxorubicin in adriamycin-resistant human myelogenous leukemia cells (K562/ADR) overexpressing $\mathrm{P}$ glycoprotein and that it inhibits the hepatobiliary excretion of doxorubicin in rats (3). On the basis of these findings from their studies and ours, we assume that azithromycin is a substrate for $\mathrm{P}$ glycoprotein, but not for CYP3A4. However, it remains unclear whether azithromycin is excreted from liver, kidney, and small intestine by $\mathrm{P}$ glycoprotein and/or other drug transporters. Little is also known about the involvement of Mrp2 in the disposition and elimination of azithromycin. 
The purpose of the present study was to investigate the involvement of the drug transporters P glycoprotein and Mrp2 in the hepatobiliary, renal, and intestinal secretion, and tissue distribution of azithromycin in rats.

\section{MATERIALS AND METHODS}

Chemicals. Azithromycin was kindly donated from Pfizer Pharm, Inc. (lot 0A0178; Tokyo, Japan). Probenecid and cyclosporine were purchased from Sigma Chemical (St. Louis, Mo.) and Novartis Pharma Co., Ltd. (Tokyo, Japan), respectively. Clarithromycin and erythromycin lactobionic acid for injection were obtained from Taisho Pharmaceutical Co., Ltd. (Osaka, Japan), and Abbott Laboratories (North Chicago, Ill.), respectively. All other reagents are commercially available and were of analytical grade. All reagents were used without further purification. Azithromycin was dissolved in $1 \mathrm{M}$ phosphoric acid and adjusted at $\mathrm{pH} 7.4$ with $1 \mathrm{~N} \mathrm{NaOH}$. Probenecid was dissolved in saline by using $0.1 \mathrm{~N} \mathrm{NaOH}$ and adjusted at $\mathrm{pH} 8.0$ with $0.05 \mathrm{~N} \mathrm{HCl}$.

Animals. Male Wistar rats (260 to $270 \mathrm{~g}$ [body weight]) were obtained from Japan SLC, Inc. (Hamamatsu, Japan). Male Eisai hyperbilirubinemic rats (EHBRs) (270 to $280 \mathrm{~g}$ ) and Sprague-Dawley rats (normal rats) (260 to $280 \mathrm{~g}$ ) of the same age as EHBRs were also obtained from the same company as described above. The rats were housed under controlled environmental conditions (temperature of $23 \pm 1{ }^{\circ} \mathrm{C}$ and humidity of $55 \% \pm 5 \%$ ) with a commercial food diet and water freely available to animals. All animal experiments were carried out in accordance with the guidelines of Nagoya University School of Medicine for the care and use of laboratory animals.

Effects of cyclosporine and erythromycin on plasma concentration-time curve of azithromycin in Wistar rats. To investigate the effects of cyclosporine and erythromycin, rats under anesthesia by intraperitoneal injection of sodium pentobarbital ( $25 \mathrm{mg} / \mathrm{kg}$ [body weight]) were cannulated with polyethylene tubes in the right jugular vein for drug administration and blood sampling. The rats received a single dose of azithromycin $(40 \mathrm{mg} / \mathrm{kg}$ [body weight]) after awakening. Azithromycin was administered $10 \mathrm{~min}$ after a single intravenous injection of cyclosporine $(20 \mathrm{mg} / \mathrm{kg})$ or $24 \mathrm{~h}$ after final intraperitoneal injection of erythromycin $(100 \mathrm{mg} / \mathrm{kg} /$ day for 3 days). Control rats received isotonic saline $(0.2$ $\mathrm{ml} / 100 \mathrm{~g})$. Blood samples $(\sim 0.2 \mathrm{ml})$ were collected at designated time intervals $(3,5,10,20,30,45,60,90,120,180,240$, and $300 \mathrm{~min}$ after injection of azithromycin). Plasma samples were obtained from the blood samples by centrifugation at $1,200 \times g$ for $5 \mathrm{~min}$ at $4^{\circ} \mathrm{C}$.

Effects of cyclosporine and probenecid on biliary and renal clearance of azithromycin in Wistar rats. Rats under light anesthesia with sodium pentobarbital $(40 \mathrm{mg} / \mathrm{kg})$ were cannulated into the right jugular vein, left carotid artery, bile duct, and urinary bladder for drug administration, blood sampling, bile collection, and urine collection, respectively. After surgical preparations, the rats received a bolus injection of azithromycin in a loading dose of $1.1 \mathrm{mg} / \mathrm{kg}$, followed by a constant-rate infusion, with a Harvard infusion pump (PHD 2000; South Natick, Mass.), of a saline solution containing $4 \%$ mannitol delivering 260 $\mu \mathrm{g}$ of azithromycin per $\mathrm{h}$ at a rate of $2 \mathrm{ml} / \mathrm{h}$ until the end of the study. The loading and maintenance doses of azithromycin were determined by preliminary biliary and renal clearance experiments. Mannitol solution was used to maintain sufficient and constant urine flow rate. After a 60-min infusion, bile and urine samples were collected at 20-min interval for $60 \mathrm{~min}$. After a 120 -min infusion, cyclosporine $(10 \mathrm{mg} / \mathrm{kg})$ or probenecid $(50 \mathrm{mg} / \mathrm{kg})$ or isotonic saline was administered intravenously. Bile and urine samples were collected in preweighed tubes at 20-min intervals from 120 to $180 \mathrm{~min}$. Blood samples were collected at the midpoints of the bile collection periods (70, 90, 110, 130, 150, and $170 \mathrm{~min}$ after the infusion was started). After a 180-min infusion, the kidney, liver, lung, and brain were removed and homogenized in a fourfold volume of isotonic saline. Plasma samples were obtained by immediate centrifugations of blood samples and were kept frozen $\left(-20^{\circ} \mathrm{C}\right)$. The volume of bile samples was measured gravimetrically with specific gravity assumed to be 1.0. This experiment was done under anesthesia with pentobarbital, and the body temperature of the animals was maintained at $37^{\circ} \mathrm{C}$ with a heat lamp.

Effect of cyclosporine on intestinal clearance of azithromycin in Wistar rats. To clarify the involvement of P glycoprotein in the intestinal efflux of azithromycin, an in situ closed-loop method was used. Rats were fasted overnight but given free access to water. The intestine was exposed by a midline abdominal incision. A 10-cm segment of the jejunum was looped at both ends after the gut was cleaned by slowly passing saline, and $5 \mathrm{ml}$ of isotonic saline or isotonic saline containing cyclosporine $(10 \mathrm{mg} / \mathrm{kg})$ was administered into the loop. After $10 \mathrm{~min}$, azithromycin $(20 \mathrm{mg} / \mathrm{kg})$ was administered via the cannula into the right jugular vein. Blood samples were collected appropriate time intervals for $60 \mathrm{~min}(3,5$,
$10,20,30,45$, and $60 \mathrm{~min}$ ). Sixty minutes after the injection of azithromycin, the solution in the loop was collected as completely as possible, and the loop was washed with saline to give a total volume of $25 \mathrm{ml}$.

Biliary excretion of azithromycin in SD rats and EHBRs. To further clarify the contribution of Mrp2 to the biliary excretion of azithromycin, normal rats and EHBRs received a bolus injection of azithromycin $(20 \mathrm{mg} / \mathrm{kg})$. Bile samples were taken at the designated periods ( 0 to 15,15 to 30,30 to 60,60 to 90 , and 90 to $120 \mathrm{~min}$ after the injection). The measurement of the volume of bile samples and this experiment were done as described above.

Protein-binding experiments. The binding of azithromycin to plasma protein was measured by using the cellulose membrane (Visking Sheet; Sanplate Corp., Osaka, Japan) with a molecular weight cutoff of 10,000 to 20,000 by the micropartition equilibrium dialysis method. Isotonic phosphate buffer ( $\mathrm{pH}$ 7.4) spiked with azithromycin $(1 \mu \mathrm{g} / \mathrm{ml})$ was dialyzed against an equal volume $(0.4 \mathrm{ml})$ of fresh rat plasma for $4 \mathrm{~h}$ at $37^{\circ} \mathrm{C}$. After the dialysis, the concentration of azithromycin in plasma and buffer was assayed for the estimation for the unbound fraction $\left(f_{U}\right)$ of azithromycin in plasma.

Tissue-binding experiments. Livers were obtained from Wistar rats. After the livers were washed with ice-cold saline, liver homogenate samples with a concentration of $40 \%$ were prepared from the portions of each liver $(\sim 2 \mathrm{~g})$ with a tight homogenizer (20 strokes up and down) in phosphate-buffered saline (PBS; $\mathrm{pH} 7.4)$ at $4^{\circ} \mathrm{C}$. The liver homogenate samples were diluted serially with PBS (40, $20,10$, and $5 \%)$. A designated concentration of azithromycin $(25 \mu \mathrm{g} / \mathrm{ml})$, which was determined based on in vivo clearance experiments, was added to each homogenate sample and was incubated at $37^{\circ} \mathrm{C}$ for $10 \mathrm{~min}$. The homogenate samples $(0.4 \mathrm{ml})$ were dialyzed against an equal volume of PBS solution for $8 \mathrm{~h}$ at $37^{\circ} \mathrm{C}$. After the dialysis, the concentration of azithromycin in homogenate and buffer was assayed for measurement of the tissue-unbound fraction $\left(\mathrm{f}_{\mathrm{T}}\right)$ of azithromycin. The bound $\left(\mathrm{C}_{\mathrm{B}}\right)$-to-unbound $\left(\mathrm{C}_{\mathrm{U}}\right)$ concentration ratio $\left(\mathrm{C}_{\mathrm{B}} / \mathrm{C}_{\mathrm{U}}\right)$ at a $100 \%$ homogenate concentration was extrapolated by plotting the values of $\mathrm{C}_{\mathrm{B}} / \mathrm{C}_{\mathrm{U}}$ against the homogenate concentration. The $\mathrm{f}_{\mathrm{T}}$ at $100 \%$ homogenate was calculated as $\mathrm{f}_{\mathrm{T}}=1 /\left(1+\mathrm{C}_{\mathrm{B}} / \mathrm{C}_{\mathrm{U}}\right.$ at $\left.100 \%\right)$.

Drug analysis. The concentration of azithromycin was determined by highperformance liquid chromatography (HPLC). The apparatus used for HPLC consisted of a Shimadzu LC-6A system (Kyoto, Japan) equipped with a coulometric electrochemical detector (Coulochem II; ESA, Chelmsford, Mass.), an LC-6A liquid pump, and an SIL-6A autoinjector. The electrochemical detector has two electrodes, set at potentials of $550 \mathrm{mV}$ (E1, screening) and $800 \mathrm{mV}$ (E2, analytical), with the gain on the detector set at $5 \mu \mathrm{A}$. The conditions were as follows: column, a Cosmocil $5 \mathrm{C}_{18}$ column $(4.6$ by $150 \mathrm{~mm}$; Nacalai Tesque, Kyoto, Japan); mobile phase, $50 \mathrm{mM}$ phosphate buffer ( $\mathrm{pH}$ 7.2)-acetonitrile $\left(55: 45\right.$ [vol/vol]) solution; column temperature (OTC-6A; Shimadzu), $30^{\circ} \mathrm{C}$; and flow rate, $1.2 \mathrm{ml} / \mathrm{min}$.

The azithromycin concentration was measured according to the reported procedures with slight modifications (28). Briefly, each sample $(50 \mu \mathrm{l})$ was deproteinized with $200 \mu \mathrm{l}$ of acetonitrile containing clarithromycin $(1 \mu \mathrm{g} / \mathrm{ml})$ as an internal standard and was then centrifuged at $6,000 \times g$ for $10 \mathrm{~min}$. The resulting supernatant $(200 \mu \mathrm{l})$ was evaporated to dryness under a nitrogen gas stream at $45^{\circ} \mathrm{C}$. The residue was reconstituted with $200 \mu \mathrm{l}$ of the mobile phase and injected into the HPLC system. This assay was shown to be linear for the concentrations tested, with correlation coefficients of $>0.99$. No interference with the peak of azithromycin was observed in any samples. The detection limit was $\sim 0.1 \mu \mathrm{g} / \mathrm{ml}$. The within-day and between-day coefficients of variation for this assay were $<8 \%$.

Data analysis. The biliary and renal clearances $\left(\mathrm{CL}_{\mathrm{BILE}}\right.$ and $\left.\mathrm{CL}_{\mathrm{R}}\right)$ were calculated by dividing the respective excretion rates by steady-state concentration in plasma $\left(\mathrm{C}_{\mathrm{SS}}\right)$ determined for that collection period. The values of $\mathrm{CL}_{\mathrm{BILE}}$ and $\mathrm{CL}_{\mathrm{R}}$ were calculated by using the mean value for three datum points during 60 $\mathrm{min}$. The tissue distribution of azithromycin is expressed as the tissue-to-plasma partition coefficient $\left(K_{\mathrm{P}}\right)$. The intestinal secretory clearance $\left(\mathrm{CL}_{\mathrm{INT}}\right)$ was calculated by dividing the amount secreted into the loop for $60 \mathrm{~min}$ by the corresponding area under the concentration-time curve (0 to $60 \mathrm{~min}$ ).

Statistical analysis. Results are expressed as the means \pm standard errors for the indicated number of experiments. Statistical comparisons were assessed by one-way analysis of variance. When the $F$ ratios were significant $(P<0.05)$, Scheffe's post hoc tests were done. $P$ values of $<0.05$ were considered statistically significant.

\section{RESULTS}

Effects of cyclosporine and erythromycin on the plasma concentration-time curve of azithromycin. Semilogarithmic plots 


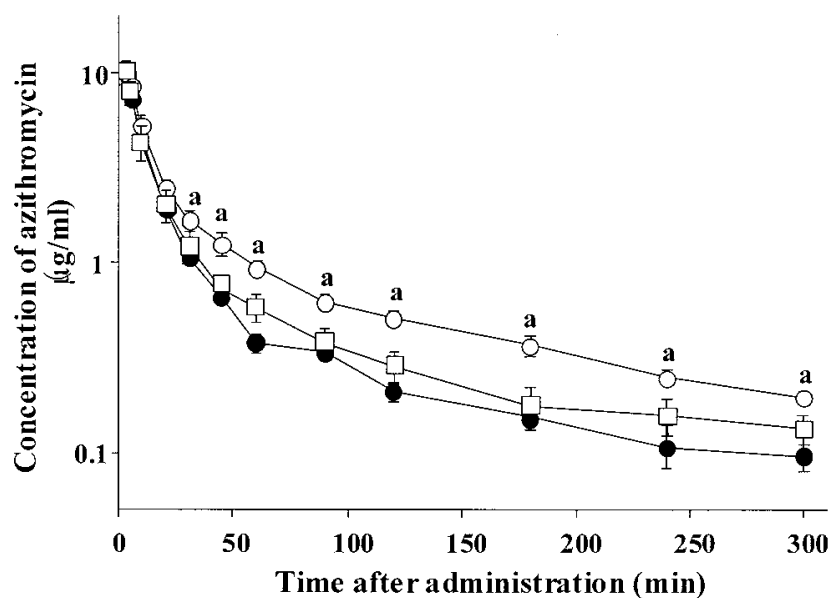

FIG. 1. Semilogarithmic plots of plasma concentration-time data of azithromycin after a single intravenous injection of azithromycin (40 $\mathrm{mg} / \mathrm{kg}$ ) in control rats and rats treated with cyclosporine or erythromycin. Azithromycin was administered intravenously $10 \mathrm{~min}$ after injection of cyclosporine $(20 \mathrm{mg} / \mathrm{kg})$ or $24 \mathrm{~h}$ after final administration of erythromycin (100 mg/kg/day for 3 days). Symbols: @, control rats; $\bigcirc$, cyclosporine-treated rats; $\square$, erythromycin-treated rats. Values are represented as means \pm the standard errors $(n=3)$. When the standard error is small, it is included in the symbol. "a" indicates values that are significantly different from the control values $(P<0.05)$.

of plasma concentration-time data for azithromycin after a single intravenous injection $(40 \mathrm{mg} / \mathrm{kg}$ ) are illustrated in Fig. 1. Pretreatment with cyclosporine $(20 \mathrm{mg} / \mathrm{kg}, 10 \mathrm{~min}$ earlier $) \mathrm{sig}$ nificantly delayed the disappearance of azithromycin from plasma and increased the concentrations in plasma, whereas pretreatment with erythromycin $(100 \mathrm{mg} / \mathrm{kg} /$ day, 3 days $) \mathrm{did}$ not.

Effects of cyclosporine and probenecid on biliary and renal clearance and tissue distribution of azithromycin. We investigated the effects of cyclosporine $(10 \mathrm{mg} / \mathrm{kg})$ and probenecid $(50 \mathrm{mg} / \mathrm{kg})$ on the biliary and renal excretion and tissue distribution of azithromycin under steady-state conditions obtained by the continuous infusion, and the parameters are summarized in Table 1. Figure 2 shows changes of $\mathrm{CL}_{\mathrm{BILE}}$ and $\mathrm{C}_{\mathrm{SS}}$ of azithromycin for $120 \mathrm{~min}$ after the injection of cyclosporine or probenecid. The systemic clearance $\left(\mathrm{CL}_{\mathrm{SYS}}\right)$, calculated by dividing the infusion rate by $\mathrm{C}_{\mathrm{SS}}$, of azithromycin in the control

TABLE 1 . Effects of cyclosporine and probenecid on biliary and renal excretion and tissue azithromycin concentrations in rats $^{a}$

\begin{tabular}{llll}
\hline \multirow{2}{*}{\multicolumn{1}{c}{ Parameter }} & \multicolumn{3}{c}{ Mean $\pm \mathrm{SE}(n=5$ to 6$)$} \\
\cline { 2 - 4 } & \multicolumn{1}{c}{ Control } & \multicolumn{1}{c}{ Cyclosporine } & \multicolumn{1}{c}{ Probenecid } \\
\hline $\mathrm{C}_{\mathrm{SS}}(\mu \mathrm{g} / \mathrm{ml})$ & $0.289 \pm 0.017$ & $0.332 \pm 0.015^{\mathrm{A}}$ & $0.337 \pm 0.019^{\mathrm{A}}$ \\
$\mathrm{CL}_{\mathrm{BILE}}(\mathrm{ml} / \mathrm{min})$ & $1.485 \pm 0.159$ & $0.086 \pm 0.021^{\mathrm{A}}$ & $0.592 \pm 0.077^{\mathrm{A}}$ \\
$\mathrm{CL}_{\mathrm{R}}(\mathrm{ml} / \mathrm{min})$ & $2.163 \pm 0.287$ & $2.019 \pm 0.072$ & $2.008 \pm 0.183$ \\
$\mathrm{Liver}(\mu \mathrm{g} / \mathrm{g})$ & $23.38 \pm 1.688$ & $24.73 \pm 1.094$ & $25.40 \pm 2.238$ \\
$\mathrm{Kidney}(\mu \mathrm{g} / \mathrm{g})$ & $17.00 \pm 1.229$ & $18.24 \pm 1.716$ & $17.03 \pm 0.390$ \\
Lung $(\mu \mathrm{g} / \mathrm{g})$ & $15.04 \pm 0.734$ & $19.31 \pm 1.387^{\mathrm{B}}$ & $15.24 \pm 0.537$ \\
\hline
\end{tabular}

${ }^{a} \mathrm{C}_{\mathrm{SS}}, \mathrm{CL}_{\mathrm{BILE}}$, and $\mathrm{CL}_{\mathrm{R}}$ represent steady-state concentration in plasma, biliary clearance, and renal clearance of azithromycin, respectively. Each value of $C_{S S}$, $C_{B I L E}$, and $C L_{R}$ of azithromycin is represented as the mean value of three points during $60 \mathrm{~min}$. Superscripts: ${ }^{\mathrm{A}}$, values that are significantly different from the control values $(P<0.05)$; ${ }^{\mathrm{B}}$, values that are significantly different from the control and probenecid values $(P<0.05)$. rats was $15.5 \mathrm{ml} / \mathrm{min}$. The values of $\mathrm{CL}_{\mathrm{BILE}}$ and $\mathrm{CL}_{\mathrm{R}}$ of azithromycin accounted for only ca. 9.6 and $14 \%$ of the $\mathrm{CL}_{\mathrm{SYS}}$, respectively. These results indicate that nonbiliary and nonrenal clearances contribute largely to the systemic clearance of azithromycin. As shown in Table 1 and Fig. 2, cyclosporine and probenecid significantly decreased the $\mathrm{CL}_{\mathrm{BILE}}$ of azithromycin by ca. 95 and $60 \%$, respectively, but did not alter the $\mathrm{CL}_{\mathrm{R}}$ of azithromycin: the overall mean values of $\mathrm{CL}_{\mathrm{BILE}}$ of azithromycin were decreased by cyclosporine and probenecid from 1.49 to $0.09 \mathrm{ml} / \mathrm{min}$ and from 1.49 to $0.59 \mathrm{ml} / \mathrm{min}$, respectively. The overall mean concentration in plasma $\left(\mathrm{C}_{\mathrm{SS}}\right)$ of azithromycin was also increased by injection of either cyclosporine or probenecid.

We further examined the tissue distribution characteristics of azithromycin and the effects of cyclosporine and probenecid on tissue distribution. The concentrations of azithromycin in tissues measured at the end of the experiment are also shown in Table 1. Azithromycin was largely distributed into the liver, kidney, and lung. In this assay, azithromycin could not be detected in the brain, suggesting that azithromycin might be limited in brain distribution. The tissue concentration and apparent tissue-to-plasma concentration ratio $\left(K_{\mathrm{P}}\right)$ of azithromycin in control rats were in the following order: liver $>$ kidney $>$ lung. Cyclosporine significantly increased the concentration of azithromycin in only the lung tissue. However, neither cyclosporine nor probenecid altered the $K_{\mathrm{P}}$ values of azithromycin (Fig. 3). The protein-binding and tissue-binding potencies for azithromycin were also measured by using the micropartition equilibrium dialysis method. The unbound plasma fraction $\left(f_{U}\right)$ of azithromycin was $0.928 \pm 0.022$, indicating that the protein-binding potency of azithromycin is negligible. On the other hand, the unbound fraction $\left(\mathrm{f}_{\mathrm{T}}\right)$ of azithromycin in liver tissue was 0.155 , suggesting high tissue-binding potency.

Biliary excretion of azithromycin in SD rats and EHBRs. To confirm whether azithromycin could be transported via Mrp2, the biliary excretion of azithromycin was determined in SD rats with Mrp2 and EHBRs lacking Mrp2. The cumulative biliary excretion-time courses of azithromycin in SD rats and EHBRs are shown in Fig. 4. The percentage of the dose excreted into the bile within the experimental period $(120 \mathrm{~min})$ in EHBRs was significantly lower compared to that in SD rats $(0.7$ and $1.2 \%$, respectively).

Effect of cyclosporine on intestinal efflux of azithromycin. We investigated whether azithromycin is actively secreted into the small intestine and the secretion is inhibited by the presence of cyclosporine by using the in situ closed-loop method. As summarized in Table 2, the apparent intestinal clearance $\left(\mathrm{CL}_{\mathrm{INT}}\right)$ of azithromycin was $0.67 \pm 0.10 \mathrm{ml} / \mathrm{min}$ and the contribution to the systemic clearance of azithromycin was very much smaller (ca. 4\%) than the biliary and renal clearance. Cyclosporine significantly decreased the $\mathrm{CL}_{\mathrm{INT}}$ of azithromycin by ca. $95 \%$ compared to the control rats.

\section{DISCUSSION}

In the present study, intravenously administered azithromycin cleared from plasma was significantly decreased in rats pretreated with cyclosporine, although pretreatment with erythromycin did not alter the clearance of azithromycin from plasma. Therefore, it was suggested that $\mathrm{P}$ glycoprotein con- 


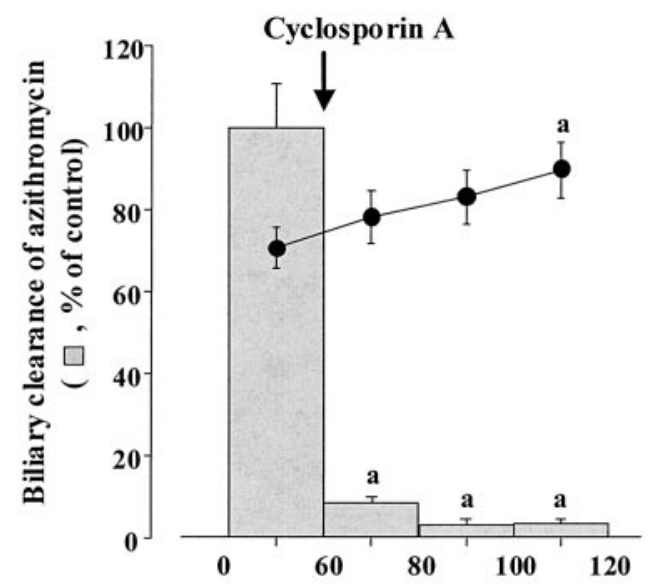

Time (min)

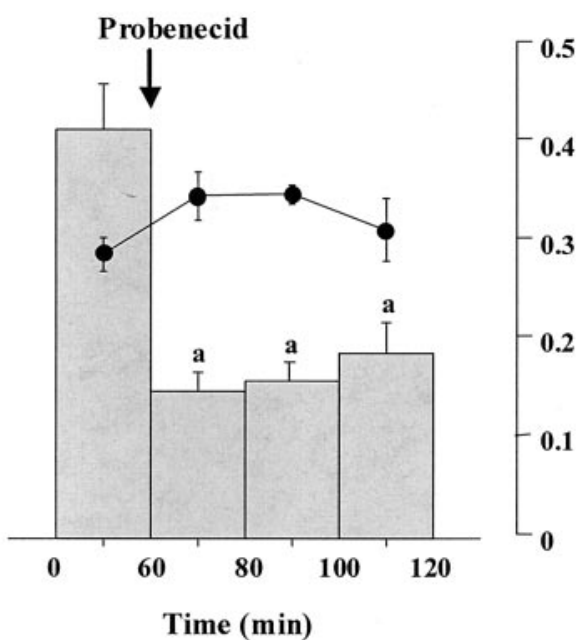

FIG. 2. Effects of cyclosporine $(10 \mathrm{mg} / \mathrm{kg})$ and probenecid $(50 \mathrm{mg} / \mathrm{kg})$ on the biliary clearance and steady-state concentrations of azithromycin in plasma. The overall mean values of biliary clearance of azithromycin in control rats and cyclosporine- and probenecid-treated rats were 1.49 , 0.05 , and $0.40 \mathrm{ml} / \mathrm{min}$, respectively. The data are the mean means \pm the standard errors $(n=5$ to 6$)$. At the time point indicated by the arrow, cyclosporine or probenecid was administered intravenously. "a" indicates values that are significantly different from the control values $(P<0.05)$.

tributes to azithromycin clearance from plasma through $\mathrm{P}$ glycoprotein-expressing tissues.

First, to identify the elimination routes of azithromycin, the biliary and renal clearance experiments were carried out under steady-state conditions. Since the liver and kidney are the two main routes of any drug elimination and it is thought that $\mathrm{P}$ glycoprotein functions effectively in these tissues, the contribution of the biliary and renal excretion to the systemic elimination of azithromycin was estimated. The obtained $\mathrm{CL}_{\mathrm{R}}$ value of azithromycin in the control rats was $\sim 1.5$-fold greater than the $\mathrm{CL}_{\mathrm{BILE}}$ value. The contribution of the $\mathrm{CL}_{\mathrm{BILE}}$ and $\mathrm{CL}_{\mathrm{R}}$ to the $\mathrm{CL}_{\mathrm{SYS}}$ of azithromycin was relatively small $(<25 \%)$, suggesting the possibility of the presence of other, unknown elimination routes of azithromycin. Considering that azithromycin is characterized as a drug with exceptionally high accumulation in tissues $(7,19)$, it could be inferred that the metabolism and/or decomposition in the tissue cells or excre- tion by breath and sweat may be the other elimination routes for azithromycin. Further studies are needed to clarify the other elimination routes of azithromycin.

Then, we investigated the contribution of $\mathrm{P}$ glycoprotein to the biliary excretion of azithromycin by using cyclosporine. Cyclosporine dramatically decreased the $\mathrm{CL}_{\mathrm{BLE}}$ of azithromycin by $95 \%$, suggesting that $\mathrm{P}$ glycoprotein might contribute largely to the hepatobiliary excretion of azithromycin. On the basis of these results, we note that substrates or inhibitors of $\mathrm{P}$ glycoprotein could inhibit largely the hepatobiliary excretion of azithromycin in humans, but not in rats, since azithromycin is reported to be mainly eliminated into the bile in humans (26).

Mrp2 mainly exist in the liver, as well as in the kidney and gut $(4,12,17)$, which functions as a potent efflux pump, like $\mathrm{P}$ glycoprotein, and the function is inhibited by cyclosporine at a higher dose (6). Therefore, there was a possibility that cyclo-

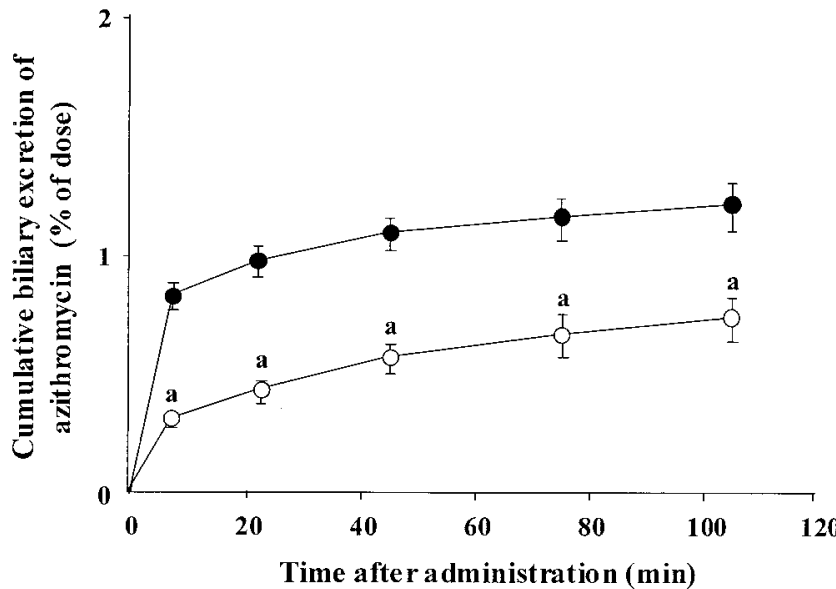

FIG. 4. Cumulative biliary excretion-time courses of azithromycin in SD rats and EHBRs. Symbols: $\bullet$, SD rats; $\bigcirc$, EHBRs. The data are the means \pm the standard errors $(n=3)$. "a" indicates values that are significantly different from the control values $(P<0.05)$.

at steady-state in control, cyclosporine-treated, and probenecidtreated rats. No significant differences in the $K_{\mathrm{P}}$ values were observed between the control and cyclosporine- or probenecid-treated rats. 
TABLE 2. Effect of cyclosporine on intestinal efflux of azithromycin in rats

\begin{tabular}{llc}
\hline \multirow{2}{*}{ Parameter $^{a}$} & \multicolumn{2}{c}{ Mean $\pm \mathrm{SE}(n=3$ to 4$)$} \\
\cline { 2 - 3 } & \multicolumn{1}{c}{ Control } & Cyclosporine \\
\hline Recovery $(\mu \mathrm{g} / 60 \mathrm{~min})^{b}$ & $51.31 \pm 9.88$ & $6.574 \pm 1.362^{c}$ \\
$\mathrm{CL}_{\mathrm{INT}}(\mathrm{ml} / \mathrm{min})$ & $0.666 \pm 0.099$ & $0.037 \pm 0.008^{c}$ \\
\hline
\end{tabular}

\footnotetext{
${ }^{a} \mathrm{CL}_{\mathrm{INT}}$ represents the intestinal clearance of azithromycin.

${ }^{b}$ That is, the content of azithromycin secreted into the loop during $60 \mathrm{~min}$.

${ }^{c}$ values that are significantly different from the control values $(P<0.05)$.
}

sporine also inhibited Mrp2-mediated biliary excretion of azithromycin to some extent. Thus, we investigated whether probenecid, an inhibitor of Mrp2 (31), could modify the biliary and renal excretion of azithromycin under steady-state conditions. In contrast to cyclosporine, probenecid did not completely inhibit the $\mathrm{CL}_{\mathrm{BILE}}$, which decreased to $40 \%$ of the levels in control rats. On the other hand, it has been reported that probenecid inhibits various types of organic anion transporting systems, including Mrp2 (18, 29, 32). To demonstrate the involvement of Mrp2 in the biliary excretion of azithromycin, the biliary excretion of azithromycin in SD rats possessing Mrp2 was compared to that in EHBRs lacking Mrp2. The in vivo biliary clearance experiment revealed that the percentage of dose excreted into the bile in EHBRs significantly lower at $60 \%$ of that in SD rats, indicating that azithromycin is, at least in part, excreted into the bile via Mrp2. It can be concluded that azithromycin is a substrate of Mrp2, as well as P glycoprotein, although the contribution of Mrp2 to the biliary excretion of azithromycin is smaller than that of $\mathrm{P}$ glycoprotein. This is the first time that Mrp2-mediated clearance has been suggested for azithromycin. These findings also suggest an overlap in substrate specificity for P glycoprotein and Mrp2, although Mrp2 is known to transport negatively charged compounds and glucuronide- and glutathione-conjugated compounds $(12,20,27,36)$.

In the present study, the $\mathrm{CL}_{\mathrm{R}}$ of azithromycin was altered by cyclosporine and probenecid in rats. The $\mathrm{CL}_{\mathrm{R}}$ value of azithromycin in the control rats was slightly smaller than the value of the glomerular filtration rate reported previously in our laboratories $(2,39)$. These results suggest that azithromycin is excreted into the urine mainly by glomerular filtration and is, in part, reabsorbed in the proximal tubular cells but not secreted actively into the urine. It is unlikely that $\mathrm{P}$ glycoprotein and Mrp2 are involved in the renal excretion of azithromycin and, therefore, renal excretion of azithromycin in humans would not be altered even if azithromycin is coadministered with substrates or modulators of P glycoprotein and Mrp2.

It has been suggested that $\mathrm{P}$ glycoprotein and Mrp2 affect the absorption and exsorption of substrates for these transporters. The role of intestinal $\mathrm{P}$ glycoprotein and Mrp2 in the absorption and exsorption of azithromycin is, however, unknown. The closed-loop experiment revealed that azithromycin was excreted into the small intestine, and the apparent intestinal clearance of azithromycin significantly decreased in the presence of cyclosporine, indicating that $\mathrm{P}$ glycoprotein is involved in the intestinal secretory transport of azithromycin. However, the exsorption into the intestinal lumen seems to be a minor route for the elimination of azithromycin. Considering that a low bioavailability of azithromycin (37\%) (26) may be explained by the possibility that azithromycin is, in part, extruded from inside the enterocytes into the intestinal lumen by $\mathrm{P}$ glycoprotein.

It has been suggested that numerous CYP3A4 substrates and P-glycoprotein substrates overlap $(13,33)$. Unlike erythromycin and clarithromycin, which are P-glycoprotein inhibitors, the present study showed that pretreatment with repeated doses of erythromycin (100 mg/kg/day for 3 days), a representative CYP3A4 inhibitor, did not alter the disappearance of azithromycin in rats from plasma, a finding which was supported by the report that azithromycin is not metabolized by CYP3A4 in humans (8). The different effects between azithromycin and erythromycin or clarithromycin may be due to differences in affinity for CYP3A4, probably deriving from their structure-related differences, although it was not clearly demonstrated in the present study.

We found that azithromycin is distributed largely into the kidney, liver, and lung, in which $\mathrm{P}$ glycoprotein and Mrp2 are constitutively expressed. We expected that the concentrations in tissue and the $K_{\mathrm{P}}$ values of azithromycin might be increased by treatment with cyclosporine or probenecid. However, no significant differences in these parameters were observed between cyclosporine- or probenecid-treated and untreated rats. In addition, the tissue-binding potency of azithromycin was found to be high (85\%). We assume that the tissue distribution of azithromycin might be dominated by the binding to azithromycin-binding proteins in the tissues. It has been reported that azithromycin is localized mainly in the lysosome and is, in part, in the cytosol of tissue cells $(5,10,24)$. We therefore presume that the observed insignificant differences in the tissue concentrations and $K_{\mathrm{P}}$ values between cyclosporine- or probenecidtreated and untreated rats are due to its sequestration in the tissues.

In conclusion, the present study is the first demonstration that $\mathrm{P}$ glycoprotein and Mrp2 are involved in the disposition of azithromycin. Although the data obtained in the present study cannot be extrapolated directly to humans, these results may provide some useful information for designing drug regimens in patients with bacterial infections.

\section{ACKNOWLEDGMENTS}

We are extremely grateful to Pfizer Pharmaceutical Company (Tokyo, Japan) and Taisho Pharmaceutical Company (Osaka, Japan) for their generous contribution of drugs.

This study was supported in part by a Grant-in-Aid for Scientific Research from the Ministry of Education, Science, Sports, and Culture of Japan (grant 15590484) and by a Grant-in-Aid for Scientific Frontier Research Project of Meijo University.

\section{REFERENCES}

1. Amsden, G. W., A. N. Nafziger, G. Foulds, and L. J. Cabelus. 2000. A study of the pharmacokinetics of azithromycin and nelfinavir when coadministered in healthy volunteers. J. Clin. Pharmacol. 40:1522-1527.

2. Ando, H., Y. Nishio, K. Ito, A. Nakao, L. Wang, Y. L. Zhao, K. Kitaichi, K. Takagi, and T. Hasegawa. 2001. Effect of endotoxin on P-glycoproteinmediated biliary and renal excretion of rhodamine-123 in rats. Antimicrob. Agents Chemother. 45:3462-3467.

3. Asakura, E., H. Nakayama, M. Sugie, Y. L. Zhao, M. Nadai, K. Kitaichi, A. Shimizu, M. Miyoshi, K. Takagi, K. Takagi, and T. Hasegawa. Azithromycin reverses anticancer drug-resistance and modifies hepatobiliary excretion of doxorubicin in rats. Eur. J. Pharmacol., in press.

4. Borst, P., R. Evers, M. Kool, and J. Wijnholds. 1999. The multidrug resistance protein family. Biochim. Biophys. Acta 1461:347-357. 
5. Carlier, M. B., I. Garcia-Luque, J. P. Montenez, P. M. Tulkens, and J. Piret. 1994. Accumulation, release and subcellular localization of azithromycin in phagocytic and non-phagocytic cells in culture. Int. J. Tissue React. 16:211220.

6. Chen, Z. S., T. Kawabe, M. Ono, S. Aoki, T. Sumizawa, T. Furukawa, T. Uchiumi, M. Wada, M. Kuwano, and S. Akiyama. 1999. Effect of multidrug resistance-reversing agents on transporting activity of human canalicular multispecific organic anion transporter. Mol. Pharmacol. 56:1219-1228.

7. Foulds, G., R. M. Shepard, and R. B. Johnson. 1990. The pharmacokinetics of azithromycin in human serum and tissues. J. Antimicrob. Chemother. 25:73-82.

8. Garey, K. W., C. A. Peloquin, P. G. Godo, A. N. Nafziger, and G. W. Amsden. 1999. Lack of effect of zafirlukast on the pharmacokinetics of azithromycin, aclarithromycin, and 14-hydroxyclarithromycin in healthy volunteers. Antimicrob. Agents Chemother. 43:1152-1155.

9. Gladue, R. P., G. M. Bright, R. E. Isaacson, and M. F. Newborg. 1989. In vitro and in vivo uptake of azithromycin (CP-62,993) by phagocytic cells: possible mechanism of delivery and release at sites of infection. Antimicrob. Agents Chemother. 33:277-282.

10. Gladue, R. P., and M. E., Snider. 1990. Intracellular accumulation of azithromycin by cultured human fibroblasts. Antimicrob. Agents Chemother. 34: 1056-1060.

11. Gorski, J. C., D. R. Jones, B. D. Haehner-Daniels, M. A. Hamman, E. M. O'Mara, and S. D. Hall. 1998. The contribution of intestinal and hepatic CYP3A to the interaction between midazolam and clarithromycin. Clin. Pharmacol. Ther. 64:133-143.

12. Gotoh, Y., H. Suzuki, S. Kinoshita, T. Hirohashi, Y. Kato, and Y. Sugiyama. 2000. Involvement of an organic anion transporter (canalicular multispecific organic anion transporter/multidrug resistance-associated protein 2) in gastrointestinal secretion of glutathione conjugates in rats. J. Pharmacol. Exp. Ther. 292:433-439.

13. Gottesman, M. M., I. Pastan, and S. V. Ambudkar. 1996. P-glycoprotein and multidrug resistance. Curr. Opin. Genet. Dev. 6:610-617.

14. Greenblatt, D. J., L. L. von Moltke, J. S. Harmatz, M. Counihan, J. A. Graf, A. L. Durol, P. Mertzanis, S. X. Duan, C. E. Wright, and R. I. Shader. 1998 Inhibition of triazolam clearance by macrolide antimicrobial agents: in vitro correlates and dynamic consequences. Clin. Pharmacol. Ther. 64:278-285.

15. Kiso, S., S. H. Cai, K. Kitaichi, N. Furui, K. Takagi, K. Takagi, T. Nabeshima, and T. Hasegawa. 2000. Inhibitory effect of erythromycin on Pglycoprotein-mediated biliary excretion of doxorubicin in rats. Anticancer Res. 20:2827-2834.

16. König, J., A. T. Nies, Y. Cui, I. Leier, and D. Keppler. 1999. Conjugate export pumps of the multidrug resistance protein (MRP) family: localization, substrate specificity, and MRP2-mediated drug resistance. Biochim. Biophys. Acta 1461:377-394.

17. Kool, M., M. de Haas, G. L. Scheffer, R. J. Scheper, M. J. van Eijk, J. A Juijin, F. Baas, and P. Borst. 1997. Analysis of expression of cMOAT (MRP2), MRP3, MRP4, and MRP5, homologues of the multidrug resistance-associated protein gene (MRP1), in human cancer cell lines. Cancer Res. 57:3537-3547.

18. Masereeuw, R., F. G. Russel, and D. S. Miller. 1996. Multiple pathways of organic anion secretion in renal proximal tubule revealed confocal microscopy. Am. J. Physiol. 271:F1173-F1179.

19. Morris, D. L., A. de Souza, J. A. Jones, and W. E. Morgan. 1991. High and prolonged pulmonary tissue concentrations of azithromycin following a single oral dose. Eur. J. Clin. Microbiol. Infect. Dis. 10:859-861.

20. Oude Elferink, R. P., D. K. Meijer, F. Kuipers, P. L. Jansen, A. K. Groen, and G. M. Groothuis. 1995. Hepatobiliary secretion of organic compounds molecular mechanisms of membrane transport. Biochim. Biophys. Acta 1241:215-268

21. Periti, P., T. Mazzei, E. Mini, and A. Novelli. 1992. Pharmacokinetic drug interactions of macrolides. Clin. Pharmacokinet. 23:106-131.

22. Schinkel, A. H., U. Mayer, E. Wagenaar, C. A. Mol, L. van Deemter, J. J. Smith, M. A. van der Valk, A. C. Voordouw, H. Spits, O. van Tellingen, J. M Zijlmans, W. E. Fibbe, and P. Borst. 1997. Normal viability and altered pharmacokinetics in mice lacking mdr1-type (drug-transporting) P-glycoproteins. Proc. Natl. Acad. Sci. USA 94:4028-4033.

23. Schinkel, A. H. E. Wagenaar, C. A. Mol, and L van Deemter. 1996. Pglycoprotein in the blood-brain barrier of mice influences the brain penetration and pharmacological activity of many drugs. J. Clin. Investig. 97: 2517-2524.

24. Schwab, J. C., Y. Cao, M. R. Slowik, and K. A. Joiner. 1994. Localization of azithromycin in Toxoplasma gondii-infected cells. Antimicrob. Agents Chemother. 38:1620-1627.

25. Seral, C., J. M., Michot, H. Chanteux, M. P., Mingeot-Leclercq, P. M., Tulkens, and F. van Bambeke. 2003. Influence of P-glycoprotein inhibitors on accumulation of macrolides in J774 murine macrophages. Antimicrob. Agents Chemother. 47:1047-1051.

26. Singlas, E. 1995. Clinical pharmacokinetics of azithromycin. Pathol. Biol. 43:505-511.

27. Takenaka, O., T. Horie, K. Kobayashi, H. Suzuki, and Y. Sugiyama. 1995 Kinetic analysis of hepatobiliary transport for conjugated metabolites in the perfused liver of mutant rats (EHBR) with hereditary conjugated hyperbilirubinemia. Pharm. Res. 12:1746-1755.

28. Taninaka, C., H. Ohtani, E. Hanada, H. Kotaki, H. Sato, and T. Iga. 2000 Determination of erythromycin, clarithromycin, roxithromycin, and azithromycin in plasma by high-performance liquid chromatography with amperometric detection. J. Chromatogr. B 738:405-411.

29. Terashita, S., T. Sawamoto, S. Deguchi, Y. Tokuma, and H. Hata. 1995. Sex-dependent and independent renal excretion of nilvadipine metabolites in rat: evidence for a sex-dependent active secretion in kidney. Xenobiotica 25:37-47.

30. Thiebaut, F., T. Tsuruo, H. Hamada, M. M. Gottesman, I. Pastan, and M. C. Willingham. 1987. Cellular localization of the multidrug-resistance gene product P-glycoprotein in normal human tissues. Proc. Natl. Acad. Sci. USA 84:7735-7738

31. Ueda, K., Y. Kato, K. Komatsu, and Y. Sugiyama. 2001. Inhibition of the biliary excretion of methotrexate by probenecid in rats: quantitative prediction of the interaction from in vitro data. J. Pharmacol. Exp. Ther. 297:10361043.

32. Ullrich, K. J., and G. Rumrich. 1997. Luminal transport step of para-aminohippurate (PAH): transport from PAH-loaded proximal tubular cells into the lumen of the rat kidney in vivo. Pflug. Arch. Eur. J. Physiol. 433:735-743.

33. Wacher, V. J., C. Y. Wu, and L. Z. Benet. 1995. Overlapping substrate specificities and tissue distribution of cytochrome P450 3A and P-glycoprotein: implications for drug delivery and activity in cancer chemotherapy. Mol. Carcinog. 13:129-134.

34. Wakasugi, H., I. Yano, T. Ito, T. Hashida, T. Futami, R. Nohara, S. Sasayama, and K. Inui. 1998. Effect of clarithromycin on renal excretion of digoxin: interaction with P-glycoprotein. Clin. Pharmacol. Ther. 64:123-128.

35. Wang, L., K. Kitaichi, S. H. Cai, K. Takagi, K. Takagi, M. Sakai, L. Yokogawa, K. Miyamoto, and T. Hasegawa. 2000. Reversal of anticancer drug resistance by macrolide antibiotics in vitro and in vivo. Clin. Exp. Pharmacol. Physiol. 27:587-593.

36. Yamazaki, M., H. Suzuki, and Y. Sugiyama. 1996. Recent advances in carrier-mediated hepatic uptake and biliary excretion of xenobiotics. Pharm. Res. 13:497-513.

37. Yumoto, R., T. Murakami, Y. Nakamoto, R. Hasegawa, J. Nagai, and M. Takano. 1999. Transport of rhodamine 123, a P-glycoprotein substrate, across rat intestine and Caco- 2 cell monolayers in the presence of cytochrome P-450 3A-related compounds. J. Exp. Pharmacol. Ther. 289:149-155.

38. Zhao, Y. L., S. H. Cai, L. Wang, K. Kitaichi, Y. Tatsumi, M. Nadai, H. Yoshizumi, K. Takagi, and T. Hasegawa. 2002. Possible involvement of P-glycoprotein in the biliary excretion of grepafloxacin. Clin. Exp. Pharmacol. Physiol. 29:167-172

39. Zhao, Y. L., X. B. Cen, M. Ito, K. Yokoyama, K. Takagi, K. Kitaichi, M Nadai, M. Ohta, K. Takagi, and T. Hasegawa. 2002. Shiga-like toxin II derived from Escherichia coli 157:H7 modifies renal handling of levofloxacin in rats. Antimicrob. Agents Chemother. 46:1522-1528. 